\title{
EDITORIAL
}

A partir deste número, Interação em Psicologia passa a ser publicada apenas em formato eletrônico. Em nosso último editorial, abordamos os motivos para tanto - que, somados, indicam que a mudança trará apenas benefícios. Lembramos também, naquele editorial, que esta mudança não atinge, de nenhuma forma, o conteúdo da revista, permanecendo inalterado nosso compromisso com a qualidade do material publicado - como bem demonstram os trabalhos que apresentamos neste número.

Aline Grill Gomes e Cesar Augusto Piccinini investigaram as implicações emocionais da ultrasonografia obstétrica para a relação materno-fetal, no contexto de normalidade fetal. Erika da Silva Ferrão, Sônia Regina Fiorim Enumo, Maria Beatriz Martins Linhares, Gizele Pereira de Sousa e Elissa Orlandi Moraes apresentam um sistema de categorias de comportamentos observáveis de crianças com dificuldade de aprendizagem, relacionado aos fatores afetivo-motivacionais exibidos durante uma prova cognitiva de modalidade assistida. Carlos Henrique Bohm e Lincoln da Silva Gimenes realizaram um exercício em análise funcional do comportamento com uma portadora de Síndrome do Intestino Irritável (SII). Yasmin Spaolonzi Daibs, Rodrigo Fernando Pereira, Deisy Ribas Emerich e Edwiges Ferreira de Mattos Silvares investigaram as relações entre a intolerância dos pais e o impacto percebido por filhos com enurese. Iasmin Zanchi Boueri e Andréia Schmidt verificaram as mudanças ocorridas no repertório de uma criança com deficiência, institucionalizada e em condição de abandono, ao passar por um procedimento focado no ensino de habilidades básicas. Cristina Delgado Rodrigues, Laura Brandão Chaves e Mary Sandra Carlotto investigaram a existência de associação entre as dimensões da síndrome de burnout e variáveis demográficas, laborais e psicossociais em professores de educação pré-escolar. Luciana Lopes de Oliveira, Dalva Cristina Aparecida de Jesus, Maria Aparecida de Lima Arruda, Maria Celestina da Cunha e Raquel Mara Araújo investigaram estereótipos de gênero entre adolescentes alunos de uma escola leiga e outra confessional, buscando identificar possíveis diferenças que a orientação da escola pudesse exercer em seus alunos na formação, manutenção e mudança dos estereótipos. Andréia Isabel Giacomozzi discute a representação social da anorexia e a identidade social construída por grupos de anoréxicas que participam de comunidades pró-anorexia no Orkut. Thiago Antonio Avellar de Aquino, Ana Carolina Diniz Alves, Andrei Alves de Aguiar e Rossana Ferreira de Oliveira Refosco apresentam correlações entre sentido da vida e concepções acerca da morte em uma amostra de estudantes universitários. Orestes Diniz Neto e Terezinha Féres-Carneiro realizaram uma revisão dos estudos sobre os marcadores e preditores da construção e dissolução da conjugalidade em uma perspectiva sistêmica, apontando suas implicações para o campo da psicoterapia de casal. Adriana Nunan, Bernardo Jablonski e Terezinha Féres-Carneiro realizaram um estudo sobre o preconceito sexual internalizado, tendo como base uma articulação entre conceitos oriundos da psicologia social e da psicanálise. Maurício da Silva Neubern destaca a importância da construção de sentido subjetivo em psicoterapia para a compreensão da experiência de sagrado. Por fim, Francielly Peron, Guilherme Previdi Olandoski, Maria Rita Drula do Nascimento, Patrícia Hobold Meurer, Rosana Angst, Sulliane Teixeira Freitas e Jocelaine Martins da Silveira fazem uma resenha do livro A guide to Functional Analytic Psychotherapy: Awareness, courage, love, and behaviorism, de autoria de Tsai, Kohlenberg, Kanter, Kohlenberg, Follette e Callaghan (2009).

Boa leitura!

\section{Alexandre Dittrich}

Editor 